\title{
Doença de Takayasu com Grave Envolvimento Cardíaco e Arterial em Pré-Escolar
}

\author{
Takayasu's Disease with Severe Heart and Arterial Involvement in a Preschool-Age Child
}

\author{
Fátima Derlene da Rocha Araújo 1,2, Zilda Maria Alves Meira², Fabiana Arantes de Araújo², Glaucia Maria \\ Vasconcelos Severiano², Kelly Nascimento Brandão ${ }^{1,2}$ \\ Hospital Municipal Odilon Behrens'; Faculdade de Medicina - Universidade Federal de Minas Gerais², Belo Horizonte, MG - Brasil
}

Neste artigo os autores descrevem um caso de arterite de Takayasu em uma criança de apenas 3 anos de idade, ressaltando-se a raridade dessa doença nessa faixa etária. A criança foi atendida em serviço de urgência em estado póscomicial de convulsão tônico-clônica generalizada. Após exame clínico detalhado, vasta propedêutica e evolução do quadro clínico, fez-se o diagnóstico de doença de Takayasu com grave envolvimento cardíaco e arterial. O relato desse caso alerta pediatras e cardiologistas para o reconhecimento dessa entidade em crianças de baixa idade, nos países em que ela é pouco diagnosticada.
The authors describe a case of Takayasu's arteritis in a child of only 3 years of age, emphasizing the rarity of this disease in this age group. The child was admitted to the emergency room in a post-convulsive state after a tonic-clonic seizure. After a detailed clinical examination, extensive diagnostic tests, and observation of the clinical evolution, the diagnosis was Takayasu's disease with severe cardiac and arterial involvement. The report warns pediatricians and cardiologists to awareness of the possibility of this disease in very small infants, in countries where it is underdiagnosed.

\section{Introdução}

A arterite de Takayasu (AT) é uma vasculite granulomatosa crônica de etiologia desconhecida, que envolve a aorta e seus principais ramos, produzindo sequelas vasculares com lesões estenóticas e/ou formação de trombos. As lesões geralmente são graves, acarretando disfunção de órgãos e, a grande maioria exige abordagem cirúrgica. É pouco diagnosticada no Brasil provavelmente por dificuldade diagnóstica, mas estudos brasileiros estimam que metade dos acometidos esteja em faixa etária menor que 20 anos $^{1}$. O caso descrito a seguir chama a atenção pelo extenso acometimento vascular com sequelas graves, em criança de baixa idade.

\section{Relato do caso}

J.E.F.S., 3 anos e 7 meses de idade, masculino, pesando 12 $\mathrm{kg}$, foi admitido em unidade de urgência em estado pós-comicial de convulsão tônico-clônica generalizada. Familiares relataram ser o primeiro episódio convulsivo e negaram febre, alterações

\section{Palavras-chave}

Arterite de Takayasu/complicações, vasculite, pré-escolar, angiografia/métodos.

Correspondência: Zilda Maria Alves Meira •

R. Roquete Mendonça, 184/401 - São José - Pampulha - 31275030 - Belo Horizonte, MG - Brasil

E-mail: zilda.m.a.m@terra.com.br

Artigo recebido em 12/08/09; revisado recebido em 07/09/09; aceito em 21/10/09. gastrointestinais, respiratórias e uso de medicamentos. A criança estava em acompanhamento em razão de baixo ganho ponderal. Não havia história familiar de epilepsia, sendo filho único de casal hígido. Epidemiologia para tuberculose (TBC) era negativa e havia "pega" vacinal (BCG) adequada.

O exame clínico evidenciou sinais de desnutrição, palidez cutâneo-mucosa leve, ausência de edema ou icterícia, bom estado geral, afebril e taquipneia leve. O exame cardiovascular mostrou ictus desviado inferiormente, hipofonese leve de bulhas, taquicardia, ausência de sopros na região precordial, abdominal e dorso. A PA variava entre 125 × 70 a 130 x 80 mmHg (percentil $>95$ para a idade, segundo Task Force, 1996). Os pulsos eram reduzidos em membros inferiores e com temperatura menor em relação aos superiores. O fígado encontrava-se a $3 \mathrm{~cm}$ do rebordo costal direito e não havia linfadenomegalias e massas abdominais.

O hemograma apresentava leucograma e plaquetometria normais, anemia leve com microcitose e hipocromia. A PCR foi negativa, VHS baixo, FAN negativo, fator reumatoide negativo, hemoculturas negativas. O ECG mostrou ritmo sinusal, sobrecarga ventricular esquerda e alterações da repolarização ventricular. $\mathrm{O}$ exame radiográfico do tórax demonstrou aumento da área cardíaca à custa do ventrículo esquerdo (VE) e sinais de congestão pulmonar (fig. 1). A tomografia computadorizada de encéfalo não evidenciou alterações. No ecocardiograma Doppler foi constatado fração de ejeção de $\mathrm{VE}=38 \%$, grande aumento de câmaras esquerdas e presença de grandes trombos no interior da cavidade do VE (fig. 1).

A ultrassonografia abdominal demonstrou redução do volume do rim direito e alterações corticais sugerindo área de infarto no polo superior deste. O duplex scan de carótidas foi normal e o Doppler de aorta abdominal evidenciou aneurisma de aorta com trombo em seu interior 


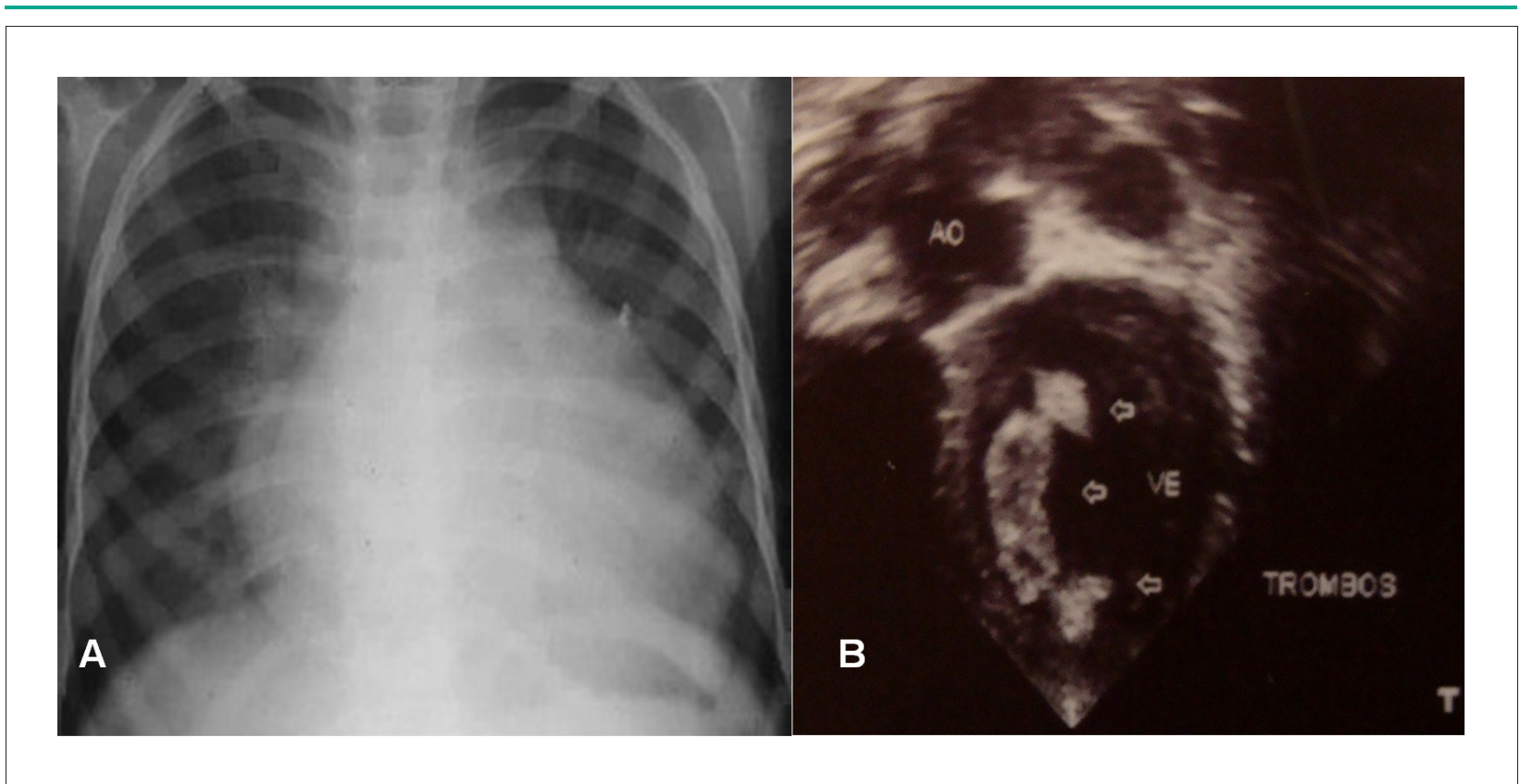

Fig. 1 - Exame radiológico do tórax (A) evidenciando cardiomegalia e estudo Doppler ecocardiograma, (B) evidenciando aumento do ventrículo esquerdo e grandes trombos em seu interior.

e vasos ilíacos e renais mal visibilizados. A angiotomografia abdominal mostrou espessamento concêntrico difuso da porção proximal e suprarrenal da aorta abdominal, além de aneurismas fusiformes das artérias ilíacas comuns (maior à direita), com presença de trombo intraluminal e hipotrofia renal à direita (fig. 2). A cineangiocoronariografia não foi realizada em razão dos riscos do acesso vascular por causa dos grandes aneurismas de artérias ilíacas.

\section{Evolução}

Houve melhora do quadro de ICC com uso de furosemida, espironolactona, digoxina e carvedilol. A criança recebeu heparinização e depois dicumarínico, não sendo visibilizados trombos intracavitários ao ecocardiograma, e não houve novos eventos tromboembólicos. A criança foi submetida a ressecção cirúrgica dos aneurismas das artérias ilíacas, com colocação de prótese na ilíaca direita e aorta abdominal. Análise anatomopatológica do segmento vascular ressecado mostrou periarterite crônica inespecífica com áreas de aterosclerose.

Durante internação a criança apresentou lesão em dorso do pé direito, sugerindo vasculite, além de febre, aumento de VHS e PCR, com melhora clínica e laboratorial após pulsoterapia com metilprednisolona. Ecocardiograma Doppler realizado após um ano de tratamento evidenciou

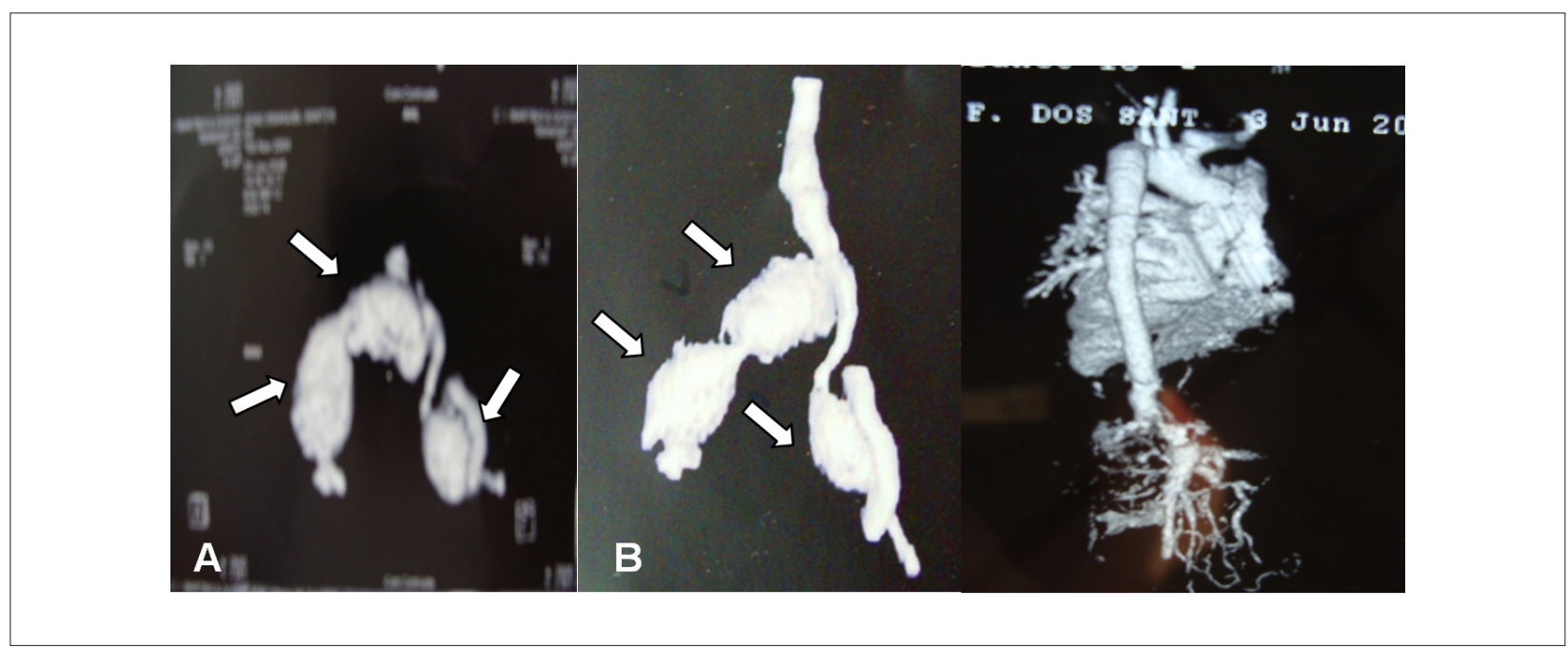

Fig. 2 - Exame angiotomográfico evidenciando três grandes aneurismas em artérias ilíacas bilateralmente $(A)$ e (B) estudo do arco aórtico e tronco braquiocefálico sem anormalidades. 
normalização da função sistólica de VE e redução das câmaras cardíacas esquerdas. A angiotomografia torácica e abdominal foi repetida e não mostrou comprometimento do arco aórtico nem do tronco braquiocefálico, mas evidenciou pouco contraste nas artérias ilíacas e grande rede de colaterais (fig. 2). Atualmente, a criança apresenta níveis pressóricos normais, função renal normal, sem ICC e ganhando peso.

\section{Discussão}

A AT foi inicialmente descrita pelo oftalmologista Mikito Takayasu, em 1908, ao observar aneurismas e anastomoses arteriovenosas na retina ${ }^{2}$. Trata-se de vasculite inflamatória, segmentar, crônica, de caráter destrutivo/degenerativo, de extensão difusa e multifocal que compromete artérias de grande e médio calibre, particularmente a aorta torácica e seus ramos maiores, além das artérias pulmonares e coronárias ${ }^{2}$. Na fase tardia, há áreas de estenoses intercaladas por dilatações aneurismáticas e segmentos normais, além de oclusões por trombos e coarctações atípicas ${ }^{1,2}$. Tais alterações acarretam isquemia em diversos territórios, especialmente cerebral, coronariano, arterial periférico e renal. Estudos sugerem que fatores imunológicos e/ou genéticos estejam implicados na gênese da doença ${ }^{3,4}$. A AT é considerada a terceira causa mundial mais comum de vasculite na infância. Cerca de três quartos dos acometidos estão entre 10 e 20 anos de idade, com maior incidência no sexo masculino $(1: 8)^{5}$.

Em geral, a doença apresenta manifestação trifásica. A primeira fase resulta do processo inflamatório agudo com sintomas inespecíficos, sem alterações dos pulsos. A segunda fase reflete a exacerbação da inflamação vascular, manifestando-se por dor no trajeto do vaso. Essas fases podem durar de meses a anos. A terceira fase é a fibrótica e as manifestações são secundárias às oclusões arteriais ${ }^{6-8}$. Associação de AT com TBC e também com artrite reumatoide, doença de Crohn, lúpus eritematoso sistêmico, tiroidite, colite ulcerativa e espondilite anquilosante é descrita por vários autores $^{4,9}$. No presente caso, não foi realizada propedêutica em relação a essas doenças em razão de ausência de outros sinais e sintomas relativos a elas.

A angiografia é o método de imagem de escolha ${ }^{5,10}$, sendo tradicionalmente usada para avaliação dos vasos comprometidos, porém tem alto risco em razão de exposição a radiações, ruptura de vasos, hemorragias e infecções. Não foi indicada pela presença de aneurismas gigantes em locais de acesso vascular para a realização do exame. Pelo baixo risco, optou-se pela angiotomografia abdominal e torácica, não sendo evidenciadas lesões em arco aórtico, tronco braquiocefálico e em toda extensão da aorta torácica, mas foi observado fluxo reduzido em ilíacas bilateralmente, com formação de rede vascular colateral.

O caso analisado preencheu os critérios diagnósticos elaborados pelo Colégio Americano de Reumatologia $(A C R)^{8,9}$ e foi classificado em tipo II segundo a classificação de Ueno e cols. ${ }^{8,9}$, modificada por Lupi e Sanchez-Torres ${ }^{8,9}$, compreendendo: envolvimento da aorta torácica, descendente e abdominal, sem envolvimento do arco aórtico ${ }^{8,9}$.

A terapêutica clínica da AT consiste no controle do processo inflamatório vascular com o uso de imunossupressores, quando em fase de atividade ${ }^{4,5}$. Na fase crônica, a revascularização cirúrgica é quase sempre necessária, com alta taxa de reestenose ${ }^{10}$. No caso descrito, houve disfunção miocárdica que respondeu bem ao tratamento clínico e ao controle da hipertensão. As alterações do sistema nervoso central foram provavelmente decorrentes do desprendimento de trombos intracardíacos, levando ao acidente vascular cerebral, acarretando hemiplegia.

Pelo caso apresentado e pela revisão de literatura, concluise que o conhecimento dessa entidade pelos pediatras e cardiologistas possibilita o diagnóstico e a conduta adequada, reduzindo a morbimortalidade. A hipótese de AT deve ser incluída no diagnóstico diferencial de casos de miocardiopatia que cursam com hipertensão arterial, acidentes vasculares cerebrais isquêmicos, assincronia de pulsos entre os membros e hipertensão renovascular, mesmo em crianças de baixa idade. Recomenda-se investigação de outras doenças, especialmente a tuberculose pela grande prevalência em nosso meio.

\section{Potencial Conflito de Interesses}

Declaro não haver conflito de interesses pertinentes.

\section{Fontes de Financiamento}

O presente estudo não teve fontes de financiamento externas.

\section{Vinculação Acadêmica}

Não há vinculação deste estudo a programas de pósgraduação.

\section{Referências}

1. Falcão S, Giorgi DMA, Favarato D, Bortolotto L, Gutierrez OS. Correlação anatomoclínica - Morte súbita em mulher de 24 anos portadora de arterite de Takayasu. Arq Bras Cardiol. 2004; 83 (2): 182-6.

2. Cid MC, Font C, Coll-Vinent B, Grau JM. Large vessel vasculitides. Curr Opin Rheumatol. 1998; 10 (1):18-28.

3. Kimura A, Kitamura H, Date Y, Numano F. Comprehensive analysis of HLA genes in Takayasu's arteritis in Japan. Int J Cardiol. 1996; 54 (Suppl): S61-9.
4. Panico MDB, Spichler ES, Rodrigues LCD. Arterite de Takayasu: aspectos clínicos e terapêuticos em 36 pacientes. J vasc bras. 2008; 7 (2): 123-30.

5. Tann OR, Tulloh RM, Hamilton MC. Takayasu's disease: a review. Cardiol Young. 2008; 18 (3): 250-9.

6. Ishikawa K. Natural history and classification of occlusive thromboarthropathy. Circulation. 1978; 57 (1): 27-35.

7. Numano F, Okawara M, Inomata H, Kobayashi Y. Takayasu's arteritis. Lancet. 
2000; 356 (9234): 1023-5.

8. Arend WP, Michel BA, Bloch DA, Hunder GG, Calabrese LH, Edworthy SM, et al. The American College of Rheumatology 1990 criteria for the classification of Takayasu arteritis. Arthritis Rheum. 1990; 33 (8): 1129-34.

9. Ishikawa K. Diagnostic approach and proposed criteria for the clinical diagnosis of Takayasu's arteriopathy. J Am Coll Cardiol. 1988; 12 (4): 964-72.

10. Milani R, Brofman P, Sandri T, Varela A, Souza JA, Emed LG. Tratamento cirúrgico sem circulação extracorpórea de arteriopatia relacionada com arterite de Takayasu envolvendo aorta e vasos da base. Arq Bras Cardiol. 2005; 85 (2): 124-7. 